\title{
A customised ARGUS VI noble gas mass spectrometer for ${ }^{40} \mathrm{Ar} /{ }^{39} \mathrm{Ar}$ geochronology
}

\author{
DOUG HAMILTON $^{1} \&$ DARREN F. MARK ${ }^{2,3}$
}

${ }^{1}$ Thermo Fisher Scientific, Bremen, Germany

${ }^{2}$ SUERC, University of Glasgow, UK

${ }^{3}$ Dept. Earth \& Environmental Science, St Andrews, UK

The Thermo Scientific ARGUS VI noble gas mass spectrometer installed at SUERC has been customised with new ion source technology to provide highsensitivity analyses of argon isotopes with the ability to control sample ionisation. The collector houses switchable $10^{11}-10^{13} \Omega$ resistor Faraday cups and a Compact Discrete Dynode electron multiplier. This contribution will discuss preliminary performance (resolution, reproducibility, precision etc.) with respect to measuring argon isotope ratios for ${ }^{40} \mathrm{Ar} /{ }^{39} \mathrm{Ar}$ dating of geological materials. We anticipate the greatest impact for ${ }^{40} \mathrm{Ar} /{ }^{39} \mathrm{Ar}$ dating will be increased accuracy and precision throughout the Geological Time and expansion of the technique into the youngest historical archives. We will further present preliminary data from the dating of mineral standards: Alder Creek sanidine, Fish Canyon sanidine and Mount Dromedary biotite (GA1550). 